\title{
Penerapan Model Sistem Dinamik Untuk Melakukan Pemeliharaan Operasional Aset Unit Transmisi Dan Visualisasi Luaran Model Dengan Menggunakan Dashboard (Studi Kasus: PT.Pln (Persero) App Semarang)
}

\author{
Pandu Satrio dan Erma Suryani \\ Departemen Sistem Informasi, Fakultas Teknologi Informasi, Institut Teknologi Sepuluh Nopember \\ (ITS) \\ e-mail: erma.suryani@is.its.ac.id
}

\begin{abstract}
Abstrak-PT. Perusahaan Listrik Negara (PT.PLN) dikenal sebagai badan usaha milik negara yang memiliki bentuk Perusahaan Perseroan (Persero) yang berkewajiban untuk menyediakan tenaga listrik bagi kepentingan umum. Sebagai salah satu yang berkewajiban untuk memberikan layanan kelistrikan untuk masyarakat luas, PT.PLN (Persero) dituntut untuk dapat terus memberikan pelayanan yang optimal agar pengguna layanan tidak terganggu dalam segala aktivitasnya. Salah satu hal yang harus diperhatikan oleh PT.PLN (Persero) adalah mengenai aset yang digunakan dalam kegiatan operasionalnya. Sebagai contoh PT.PLN (Persero) APP Semarang, yang merupakan unit transmisi memiliki aset yang bekerja secara penuh untuk dapat menunjang kegiatan operasionalnya setiap hari. Namun, setiap aset yang digunakan pasti memiliki umur asetnya sendiri dan membutuhkan perbaikan maupun pergantian unit pada waktu tertentu. Hal ini dapat menyebabkan beberapa permasalahan seperti kerusakan pada aset yang disebabkan oleh beberapa faktor, aset yang sudah dimakan usia ataupun komponen aset yang dicuri oleh pihak tidak bertanggung jawab. Akibatnya, dapat menyebabkan pemadaman yang secara tidak langsung menggangu layanan yang diberikan sehingga tidak optimal. Untuk mengatasi permasalahan tersebut, maka dilakukanlah manajemen aset untuk pemeliharaan dan monitoring terhadap aset yang dimiliki oleh unit transmisi. Pemeliharaan dan monitoring aset tersebut dilakukan dengan menggunakan sistem dinamik untuk memahami permasalahan yang ada dengan lebih jelas, kemudian dilakukan simulasi model agar mendapatkan skenario alternatif terbaik untuk perusahaan. Selanjutnya agar informasi yang dihasilkan lebih mudah dipahami, maka digunakanlah dashboard sebagai media untuk penyampaian informasi agar dapat mempermudah decision maker dalam mengambil keputusan untuk perusahaan. Dengan hasil skenario yang didapatkan dari permodelan dan simulasi yang telah dilakukan, PT. PLN (Persero) APP Semarang dapat menggunakan hasil tersebut untuk melakukan pemeliharaan dan monitoring pada asetnya dengan lebih optimal kedepannya.
\end{abstract}

Kata Kunci-Sistem Dinamik, Manajemen Aset, Unit Transmisi, Pemeliharaan Aset, Dashboard.

\section{PENDAHULUAN}

CETIAP perusahaan memiliki aset yang digunakan untuk menjalankan proses bisnis dari perusahaan tersebut. Aset sendiri merupakan sumber daya yang dimiliki oleh perusahaan sebagai akibat dari kejadian pada masa lampau dan memiliki manfaat ekonomi untuk masa depan yang diharapkan akan diperoleh perusahaan [1]. Dengan kata lain, aset adalah sesuatu yang sangat berharga yang dimiliki oleh tiap-tiap perusahaan. Semakin tinggi skala bisnis sebuah perusahaan maka aset yang dikelola pun meningkat. Pengelolaan aset bergantung pada kemampuan menentukan komponen kritis dan menentukan pendefinisian kondisi aset [2]. Dengan mengoptimalkan pengelolaan aset tersebut maka sebuah perusahaan dapat meminimalkan risiko dan biaya serta meningkatkan nilai siklus hidup suatu aset [3]. Tak terkecuali dengan PT. Perusahaan Listrik Negara Persero (PT.PLN) sebagai Badan Usaha Milik Negara yang memiliki bentuk Perusahaan Perseroan (Persero) berkewajiban untuk menyediakan tenaga listrik bagi kepentingan umum. Aset yang dikelola oleh PT.PLN berperan dalam memberikan pelayanan yang optimal untuk masyarakat yang menggunakannya. Sebagai satu-satunya perusahaan yang di berikan tugas dan wewenang sebagai pengelola usaha ketenagalistrikan di Indonesia, PT. PLN memiliki kegiatan operasional mulai dari pembangkit, transmisi dan distribusi sampai kepada penjualan [4].

Dengan banyaknya aset yang digunakan untuk kegiatan operasionalnya, tidak menutup kemungkinan terjadi beberapa permasalahan terhadap kinerja dari aset tersebut. Kemungkinan-kemungkinan tersebut dapat terjadi mengingat seluruh aset yang digunakan bekerja secara rutin setiap harinya. Padahal setiap aset yang bekerja dan digunakan secara rutin memiliki umur asetnya sendiri yang membutuhkan perbaikan atau pergantian unit pada waktu tertentu. Salah satu yang paling sering terjadi adalah masalah pemadaman pada unit yang sedang bekerja. Hal ini dapat disebabkan oleh beberapa kemungkinan seperti kerusakan pada komponen aset, aset yang sudah dimakan usia, maupun komponen dari aset tersebut dicuri ketika melakukan kegiatan operasionalnya [5]. Apabila aset 
tersebut berhenti beroperasi, maka kegiatan operasional dari aset lainnya yang saling berhubungan juga akan terhenti dan mengakibatkan jaringan listrik yang dibutuhkan masyarakat terganggu. Hal ini menjadi permasalahan yang harus dihindari oleh PT.PLN agar pelayanan yang dihasilkan tetap optimal.

Berdasarkan permasalahan diatas, mahasiswa selaku peneliti berniat untuk melakukan penyelesaian permasalahan tersebut. Salah satu bentuk penyelesaian permasalahan tersebut adalah melakukan pemeliharaan terhadap aset dengan melakukan manajemen aset. Manajemen aset dirasa perlu untuk dapat mengetahui informasi mengenai umur aset, pemanfaatan aset dengan optimal yang dinilai dari umur aset dan permasalahan yang mungkin akan timbul pada aset tersebut. Penelitian ini sendiri memiliki tujuan untuk memodelkan aset saat ini ke dalam simulasi yang dapat membantu mempermudah decision maker untuk membuat keputusan agar mendapatkan keuntungan yang optimal terhadap aset yang digunakan nantinya [6]. Untuk membantu memodelkan aset tersebut, maka penelitian ini menggunakan sistem dinamik agar mendapatkan hasil simulasi yang paling sesuai dengan kebutuhan aset. Sistem Dinamik sendiri merupakan sebuah metodologi untuk dapat memahami suatu masalah yang kompleks. Metodologi ini juga menitik beratkan pada pengambilan keputusan dan melihat bagaimana keputusan tersebut dapat menentukan permasalahan yang selanjutnya dapat dimodelkan oleh sistem secara dinamik [7]. Kemudian hasil simulasi yang telah optimal yakni permodelan yang sudah memiliki hasil sesuai dengan yang diharapkan dibuat waktu penjadwalan untuk melakukan monitoring dan pemeliharaan yang nantinya ditampilkan melalui alat bantu dashboard agar lebih mudah untuk penyampaian informasi yang dibutuhkan dan lebih mudah untuk dikelola oleh perusahaan.

\section{DASAR TEORI}

\section{A. Aset}

Aset merupakan sumber daya yang dikuasai oleh perusahaan sebagai akibat dari peristiwa masa lalu dan dari mana manfaat ekonomi di masa depan diharapkan akan diperoleh perusahaan [1]. Aset sendiri memiliki beberapa klasifikasinya masingmasing, yakni aset lancar, investasi jangka panjang, aset tetap, dan aset tidak berwujud, pembagian ini merupakan klasifikasi menurut Weygant et al [8].

\section{B. Permodelan dan Simulasi}

Model didefinisikan sebagai suatu deskripsi logis tentang bagaimana sistem bekerja atau komponen-komponen berinteraksi. Salah satu syarat pokok untuk mengembangkan model adalah dengan menemukan variables apa yang penting dan tepat. Penemuan variables sendiri sangat erat kaitannya dengan pengkajian terhadap hubungan-hubungan yang terdapat di antara variables [5]. Dengan membuat model dari suatu sistem maka diharapkan dapat lebih mudah untuk melakukan analisis. Hal tersebut tak lain merupakan prinsip dari permodelan sendiri, yaitu tujuan dari sebuah permodelan adalah untuk dapat mempermudah analisis dan pengembangannya. Untuk mempelajari sistem dan model dan macam-macam perbedaan perilakunya, seluruhnya dapat dilakukan dengan menggunakan permodelan [7]. Simulasi dapat digunakan untuk melakukan eksperimen dengan kondisi untuk mencari komentar terbaik dari komponen-komponen sistem. Karena apabila melakukan eksperimen secara riil, akan memerlukan waktu yang sangat lama dan biaya yang mahal.

\section{Sistem Dinamik}

Sistem dinamik merupakan metodologi untuk mengabstraksiskan suatu fenomena di dunia sebenarnya ke model yang lebih eksplisit. Model sistem dinamik dapat dibentuk yang disebabkan oleh hubungan sebab-akibat (casual) yang kemudian mempengaruhi struktur yang terdapat dalam sistem, baik secara langsung antar dua struktur, maupun akibat dari hubungan - hubungan yang terjadi pada beberapa struktur, sampai pada akhirnya membentuk umpan-balik (casual loop).

\section{Diagram Kausatik}

Causal Loop Diagram merupakan sebuah model yang banyak digunakan untuk memecahkan permasalahan dengan pendekatan sistem yang mempertimbangkan kompleksitas dinamis dari sistem aktual atau untuk mendukung pendekatan sistem dinamik. Pembuatan diagram kausatik ini sendiri memiliki panah-panah yang menghubungkan variabel satu dan lainnya dengan tanda positif maupn negatif diantaranya. Tanda positif sendiri memliki arti perubahan yang disebabkan oleh suatu variabel akan mengubah variabel lain secara searah kemudian untuk tanda negatif memiliki arti perubahan yang disebabkan oleh suatu variabel akan merubah variabel lainnya ke arah yang berlawanan dari tanda tersebut [9].

\section{E. Verifikasi dan Validasi}

Verifikasi ini sendiri dilakukan untuk menjamin kebenaran suatu model berdasarkan nilai matematis dan konsisten secara logika. Sedangkan validasi model merupakan sebuah tindakan yang dilakukan untuk dapat mengetahui dan membuktikan bahwa proses atau metode yang dipakai dapat memberikan hasil yang konsisten sesuai dengan spesifikasi yang telah ditetapkan dan terdokumentasikan dengan baik. Menurut Law dan Kelton [10] validasi merupakan sebuah proses untuk menentukan apakah model konseptual mempresentasikan sistem nyata dengan tepat atau tidak. Berikut adalah rumus yang dapat digunakan untuk mengetahui model yang dikaji sudah valid:

\section{Melakukan perbandingan rata-rata (Mean Comparison)}

$$
E 1=\frac{|\bar{S}-\bar{A}|}{\bar{A}}
$$

Dimana:

$\bar{S}=$ nilai rata-rata hasil simulasi

$\bar{A}=$ nilai rata-rata data

Dan sebuah model dianggap valid apabila memiliki nilai E1 $\leq$ $5 \%$

2. Melakukan perbandingan Variasi Amplitudo (\% Error Variance)

$$
E 2=\frac{|S s-S a|}{S a}
$$

Dimana:

Ss $=$ Standar deviasi model

$\mathrm{Sa}=$ Standar deviasi data

Dan sebuah model dianggap balid apabila memiliki nilai E2 $\leq$ $30 \%$ 


\section{F. Visualisasi Dashboard}

Menurut Few [11], Dashboard merupakan sebuah tampilan secara visual berdasarkan informasi penting yang dibutuhkan untuk mencapai satu atau lebih tujuan, kemudian informasi tersebut digabungkan dalam satu layar dan menjadi infomasi yang sesuai kebutuhan juga dapat dilihat secara sekilas. Dengan menampilkan secara visual, informasi yang disajikan harus dirancang sebaik mungkin, sehingga setiap dashboard tersebut ditampilkan, manusia dapat secara cepat untuk memahami maknanya dengan benar. Dashboard merupakan sebuah tampilan pada satu layar penuh yang memberikan informasi secara rinci dan bersifat kritis, dan hanya dengan melihat dashboard tersebut, kita dapat mengetahui informasi yang dibutuhkan. Pada dasarnya kombinasi yang terdapat pada dashboard adalah teks dan grafik namun memang lebih ditekankan untuk menampilkan grafik [11].Terdapat beberapa tahapan yang diperlukan untuk dapat membuat dashboard yang sesuai dengan keadaan aktual dari informasi yang akan ditampilkan, diantaranya adalah sebagai berikut [12]:

1. Identifikasi kebutuhan

2. Analisis dan perancangan

3. Perancangan informational dashboard

4. Perancangan prototype dashboard

\section{METODOLOGI}

Penelitian ini dikerjakan atas susunan dari tahapan-tahapan yang telah ditentukan. Tahapan-tahapan pengerjaan pada penelitian ini adalah sebagai berikut:

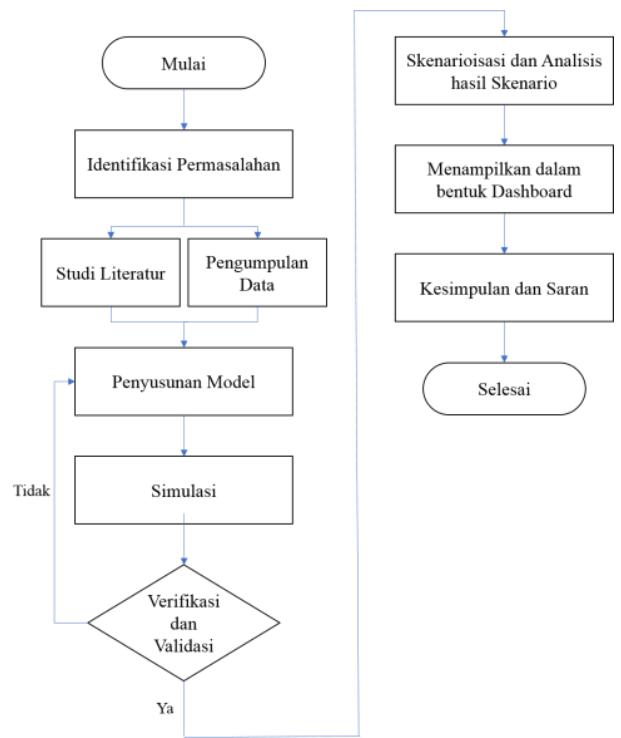

Gambar 1. Metodologi Penelitian

\section{MODEL DAN IMPLEMENTASI}

\section{A. Diagram Kausatik}

Proses identifikasi variabel yang memiliki hubungan dengan sistem utama yaitu proses pemeliharaan perlu dilakukan untuk mengetahui variabel-variabel yang dapat mempengaruhi proses pemeliharaan tersebut. Pada studi ini, kondisi aset unit transmisi (asset condition), pemeliharaan keandalan aset (maintain reability), bergantung keapda proses pemeliharaan aset unit (maintenance asset). Beberapa variabel yang telah disebutkan tersebut memiliki peran untuk memberi tahu proses manajemen aset yang telah dilakukan oleh pihak PT. PLN (Persero) APP Semarang. Variabel yang digunakan dalam model dasar dari simulasi ini merupakan hasil penyesuaian variabel dengan sistem nyata yang berjalan di lapangan. Hasil permodelan simulasi model dasar berupa Causal Loop diagram memiliki gambaran sebagai berikut:

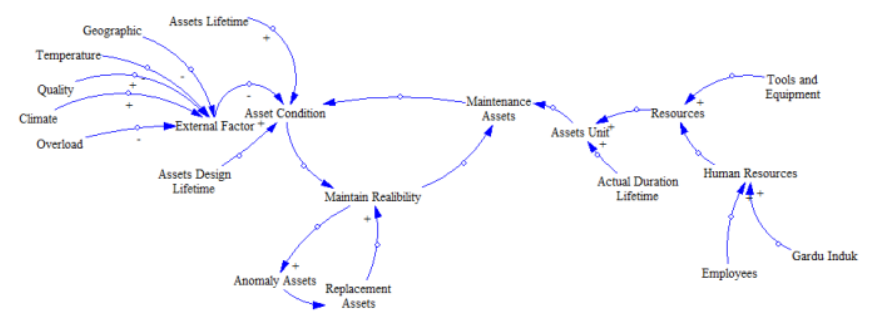

Gambar 2. Diagram Kausatik

\section{A. Basemodel}

Pada Basemodel manajemen aset dibagi beberapa submodel seperti pada gambar dibawah ini:

\section{1) Sub-model Condition Effect}

Merupakan faktor eksternal dan acceleration factor yang mempengaruhi kondisi aset

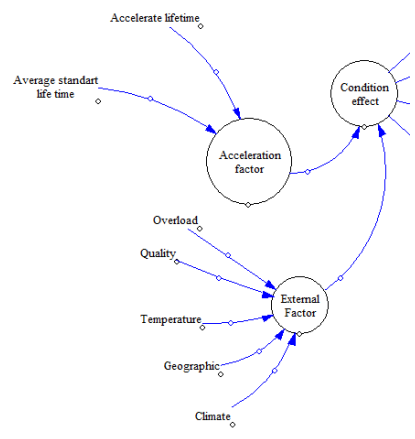

Gambar 3. Condition effect

\section{2) Sub-model Current Transformer}

Merupakan submodel yang menggambarkan kondisi aset CT

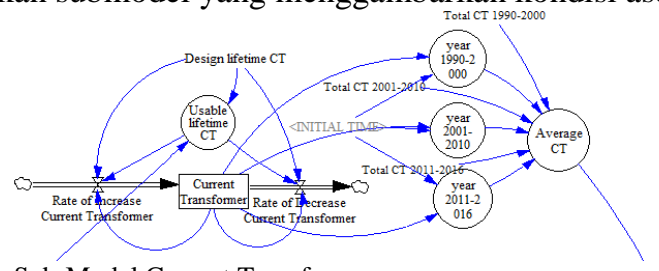

Gambar 4. Sub-Model Current Transformer

3) Sub-model Lightning Arrester

Merupakan submodel yang menggambarkan kondisi aset LA

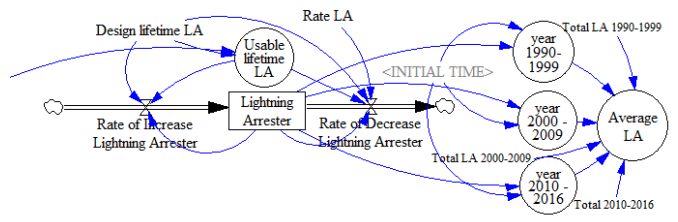

Gambar 5. Sub-Model Lightning Arrester 
4) Sub-model Disconnecting Switch

Merupakan submodel yang menggambarkan kondisi aset DS

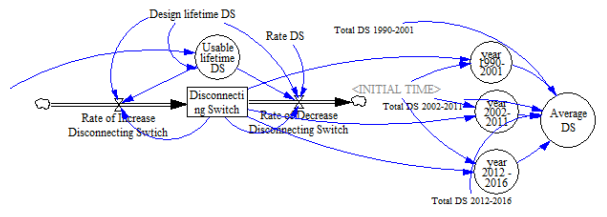

Gambar 6. Sub-Model Disconnecting Switch

\section{5) Sub-model Circuit Breaker}

Merupakan submodel yang menggambarkan kondisi aset CB

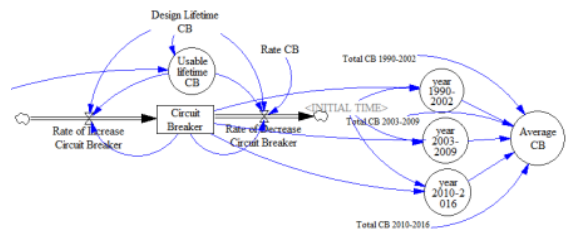

Gambar 7. Sub-Model Circuit Breaker

\section{6) Sub-model Anomali Aset}

Merupakan submodel yang menggambarkan jumlah permasalahan anomali yang terjadi

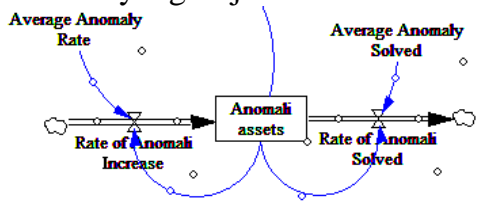

Gambar 8. Sub-Model Anomali Aset

\section{7) Sub-model Maintenance Asset}

Merupakan submodel yang menggambarkan formulasi durasi pemeliharaan aset.

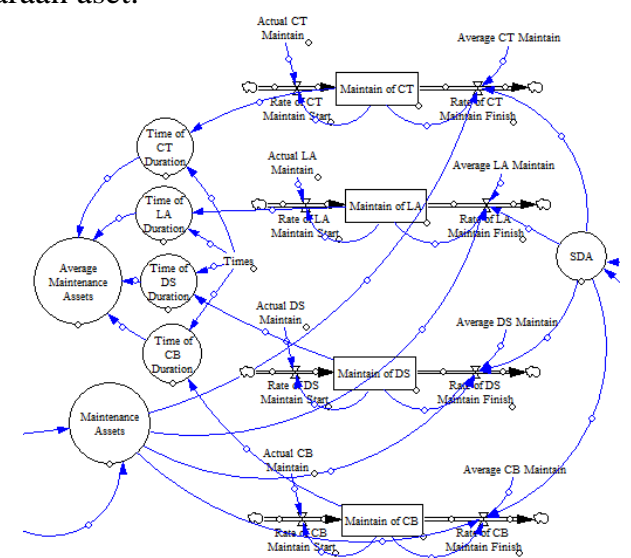

Gambar 9. Sub-Model Maintenance Asset

8) Sub-model SDA

Merupakan faktor yang mempengaruhi durasi pemeliharaan

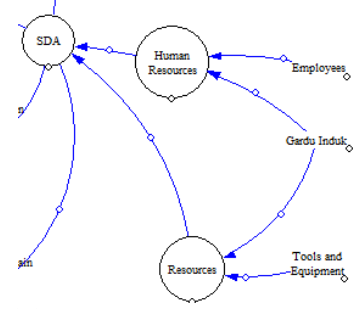

Gambar 10. Sub-Model SDA

\section{B. Verifikasi dan Validasi}

Pada pengerjaan studi ini, uji validitas yang dilakukan adalah dengan pengujian behaviour validity test dimana mean variance memiliki nilai lebih rendah dari 5\% dan error variance memiliki nilai lebih rendah dari $30 \%$. Sub-model yang dilakukan uji validitas ini adalah Time of Duration CT, Time of Duration LA, Time of Duration DS, Time of Duration CB dan Anomali aset. Dengan demikian, model yang dihasilkan dapat digunakan untuk meningkatkan keandalan aset unit transmisi.

- $\quad$ Time of Duration CT: E1 $=0.29 \%, \mathrm{E} 2=16.64 \%$.

- $\quad$ Time of Duration LA: E1 $=0.42 \%, \mathrm{E} 2=10.84 \%$.

- $\quad$ Time of Duration DS: E1 $=1.41 \%, \mathrm{E} 2=5.17 \%$.

- $\quad$ Time of Duration CB: E1 $=0.22 \%, \mathrm{E} 2=2.85 \%$.

- Anomali Aset: $\mathrm{E} 1=2.34 \%, \mathrm{E} 2=0.82 \%$

C. Pengembangan Skenario

Skenario yang dibentuk merupakan pengembangan yang telah dilakukan berdasarkan hasil yang didapatkan dari simulasi pada basemodel yang telah terverifikasi dan tervalidasi. Terdapat berbagai bentuk skenario yang dapat dilakukan untuk memperbaiki kondisi basemodel yang digunakan, salah satu caranya adalah dengan menambahan variabel yang mempengaruhi proses pemeliharaan aset unit transmisi. Terdapat 2 skenario yang digunakan yaitu:

1. Skenario struktur penggantian aset (replacement assets) pada saat persentase kondisi aset yang digunakan sudah dibawah 50\% mengikuti jumlah total aset yang dipasang pada saat itu.

2. Skenario struktur perbaikan terhadap aset yang tidak beroperasi/rusak untuk meningkatkan persentase kondisi aset.

\section{1) Skenario 1}

Skenario pertama yang akan diterapkan adalah skenario untuk melakukan penggantian unit aset pada saat persentase kondisi asetnya sudah dibawah 50\% dari hasil yang didapatkan pada basemodel. Penggantian aset yang akan dilakukan adalah sebagai berikut:

- Penggantian aset unit Current Transformer pada tahun 2017 dikarenakan kondisi CT pada tahun tersebut memiliki persentase $36 \%$

- Penggantian aset unit Lightning Arrester pada tahun 2017 dikarenakan kondisi LA pada tahun tersebut memiliki persentase dibawah $20 \%$

- Penggantian aset unit Disconnecting Switch pada tahun 2017 dikarenakan kondisi DS pada tahun tersebut memiliki persentase $29 \%$

- Penggantian aset unit Circuit Breaker pada tahun 2018 dikarenakan kondisi CB pada tahun tersebut memiliki persentase $45 \%$

\section{2) Skenario 2}

Skenario kedua ini memiliki tujuan untuk merawat aset yang sedang dalam kondisi tidak prima, baik dalam kondisi sedang rusak maupun tidak beroperasi. Penambahan variabel Impact of Maintenance Effectiveness dapat dilakukan apabila terdapat aset dengan kondisi buruk (Poor Condition Aset) yang dapat dilakukan perawatan [10]. Perawatan yang dilakukan pada aset seperti melakukan pengisian dan penyaringan pada trafo agar 
mengetahui kualitas tegangan yang dihasilkan, membersihkan permukaan insulator pada aset lightning arrester dan perbaikan lainnya yang akan dijelaskan sebagai berikut:

Rekomendasi perawatan aset tiap tahun yang dapat dilakukan adalah sebagai berikut [13]:

a. Current Transformer - Melakukan pembersihan aset, melakukan uji breaker, melakukan pemeriksaan termografis, pengisian dan penyaringan dan melakukan pengujian.

b. Lighning Arrester - Melakukan pembersihan permukaan insulator, memperbaiki kondisi permukaan glaze insulator, melakukan pemeriksaan kondisi counter arrester yang pecah dan retak dan melakukan pengujian.

c. Disconnecting Switch - Melakukan pemeriksaan kondisi sekring, melakukan pembersihan heater, melakukan pembersihan pada isolator dan terminal wiring, dan melakukan pengecekan kelengkapan roda penggerak PMS, sistem lock mekanik, engkol, dan roda gigi.

D. Analisa Hasil

Analisa dilakukan pada luaran yang dihasilkan dalam vensim dengan beberapa skenario. Berikut adalah hasil perbandingan:

1) Perbandingan kondisi pada Aset CT

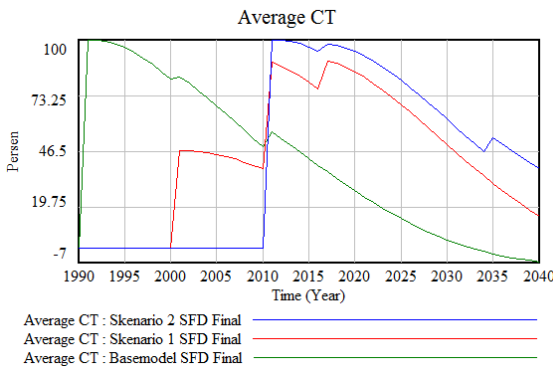

Gambar 11. Kondisi Aset CT

2) Perbandingan kondisi pada Aset LA

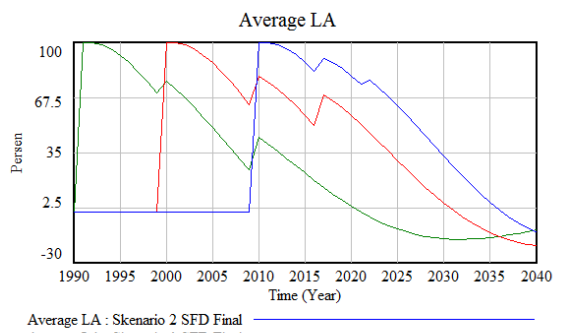

Average LA : Skenario 1 SFD Final

Gambar 12. Kondisi Aset LA

3) Perbandingan kondisi pada Aset DS

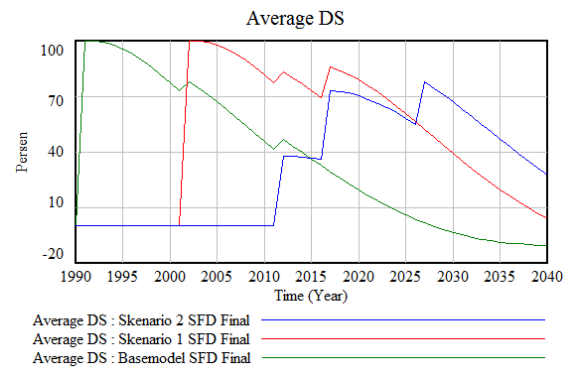

Gambar 13. Kondisi Aset DS

\section{4) Perbandingan kondisi pada Aset CB}

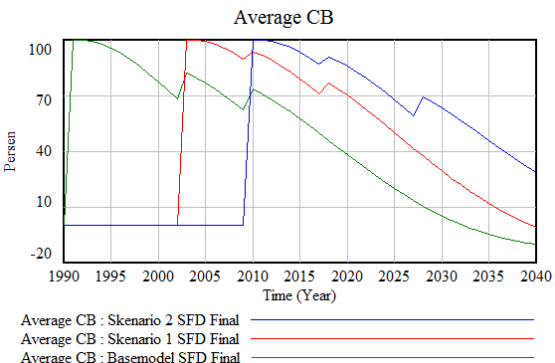

Gambar 14. Kondisi Aset CB

\section{5) Perbandingan pada kondisi Anomali aset}

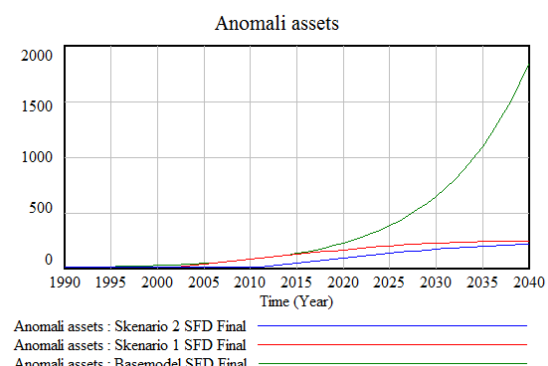

Anomali assets. Skenario 1 SFD Final

Gambar 15. Kondisi Anomali Aset

6) Perbandingan durasi pemeliharaan

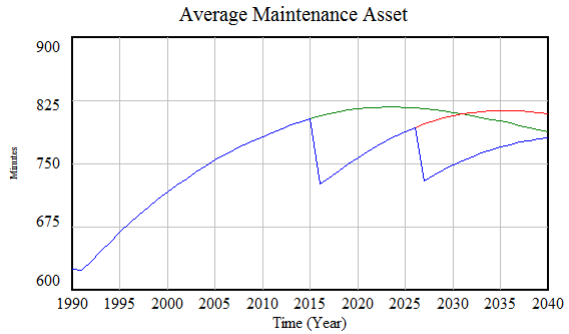

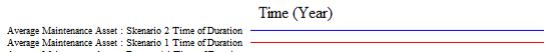

Gambar 16. Kondisi Durasi Pemeliharaan

\section{PEMBUATAN DASHBOARD}

\section{A. Pemrosesan Data}

Tahapan pemrosesan data untuk dashboard dilakukan untuk mengetahui hubungan yang dapat ditemukan antar variabel yang dihasilkan untuk selanjutnya dibuatkan menjadi sebuah desain dashboard sesuai dengan output yang didapatkan dari model yaitu basemodel, skenario 1 dan skenario 2. Data yang akan digunakan dalam dashboard adalah sebagai berikut:

- Hasil simulasi variabel aset kondisi : Current Transformer, Lightning Arrester, Disconnecting Switch dan Circuit Breaker.

- Hasil simulasi variebel anomali aset.

- Hasil simulasi variabel Time of Duration: Current Transformer, Lightning Arrester, Disconnecting Switch dan Circuit Breaker.

\section{B. Implementasi Dashboard}

Implementasi dashboard yang akan dibuat merupakan pengembangan yang dilakukan berdasarkan hasil dari luaran 
pada aplikasi vensim yang telah dilakukan validasi. Luaran tersebut kemudian disimpan dalam bentuk excel sebagai database untuk membuat dashboard. Pada studi ini, dashboard yang digunakan untuk dapat merepresentasikan informasi yang dihasilkan menggunakan jenis strategis dashboard karena luaran yang dihasilkan dalam bentuk dashboard, nantinya digunakan untuk dapat menentukan keputusan yang praktis dan dapat memberikan prediksi terhadap aset kedepannya, sehingga memberikan peluang untuk mencapai tujuan strategis yang diinginkan yaitu agar kondisi aset tetap optimal.

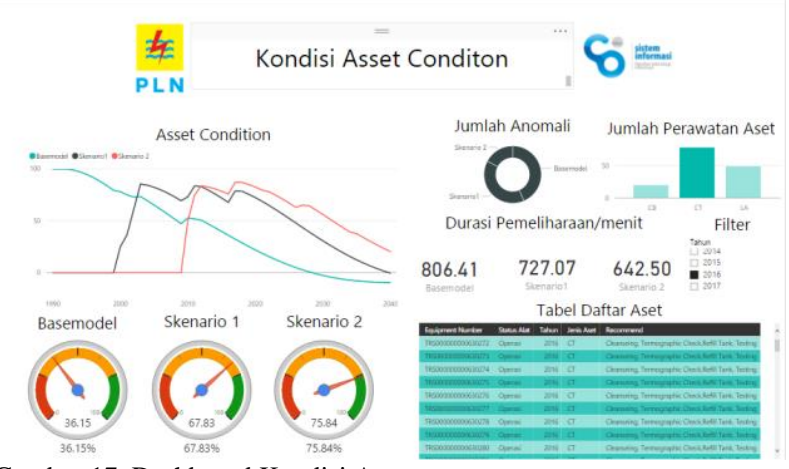

Gambar 17. Dashboard Kondisi Aset

\section{KESIMPULAN}

Beberapa kesimpulan yang didapatkan dalam pengerjaan studi ini adalah sebagai berikut:

1. Pada pengerjaan studi ini, uji validitas yang dilakukan adalah dengan pengujian behaviour validity test dimana mean variance memiliki nilai lebih rendah dari $5 \%$ dan error variance memiliki nilai lebih rendah dari $30 \%$. Sub-model yang dilakukan uji validitas ini adalah Time of Duration CT, Time of Duration LA, Time of Duration DS, Time of Duration CB dan Anomali aset. Dengan demikian, model yang dihasilkan dapat digunakan untuk meningkatkan keandalan aset unit transmisi.

- $\quad$ Time of Duration CT: E1 $=0.29 \%, \mathrm{E} 2=16.64 \%$.

- Time of Duration LA: E1 $=0.42 \%, \mathrm{E} 2=10.84 \%$.

- Time of Duration DS: E1 $=1.41 \%, \mathrm{E} 2=5.17 \%$.

- Time of Duration CB: E1 $=0.22 \%, \mathrm{E} 2=2.85 \%$.

- $\quad$ Anomali Aset: E1 $=2.34 \%, \mathrm{E} 2=0.82 \%$

2. Selanjutnya adalah melakukan replacement aset pada aset yang memiliki persentase kondisi dibawah 50\% sebagai berikut: Current Transformer pada tahun 2017, Lightning Arrester pada tahun 2017, Disconnecting Switch pada tahun 2017 dan Circuit Breaker pada tahun 2018 yang dapat dilihat dari kondisi aset karena sudah dibawah 50\%.

3. Kembali melakukan replacement aset pada aset yang kondisinya masih dibawah 50\% sampai pada tahun 2040 (disebabkan setiap pemasangan aset baru rata-rata umur lifetime aset adalah 25 tahun) untuk aset seperti current transformer pada tahun 2035, Lightning Arrester pada tahun 2022, Disconnecting Switch pada tahun 2027, dan Circuit Breaker pada tahun 2028.

4. Menggabungkan skenario 1 dan skenario 2 yaitu dengan melakukan replacement pada aset dan melakukan perawatan pada aset yang memiliki kondisi tidak prima karena dengan menggabungkan kedua skenario tersebut maka hasil yang didapatkan adalah sebagai berikut:

Table 1.

Hasil Skenario

\begin{tabular}{llll}
\hline \hline Jenis Aset & Basemodel & Skenario 1 & Skenario 2 \\
\hline Current Transformer & $36 \%$ & $89 \%$ & $98 \%$ \\
Lightning Arrester & $14 \%$ & $68 \%$ & $90 \%$ \\
Disconnecting Switch & $29 \%$ & $85 \%$ & $73 \%$ \\
Circuit Breaker & $49 \%$ & $70 \%$ & $86 \%$ \\
Anomali Aset & 167 kasus & 143 kasus & 67 kasus \\
Average Maintenance & 809 menit & 733 menit & 650 menit \\
Duration & & & \\
\hline \hline
\end{tabular}

5. Pembuatan dashboard berdasarkan ketentuan KPI yang telah ditentukan oleh pihak PT. PLN (Persero) APP Semarang. Pembuatan dashboard dilakukan dengan hasil yang didapatkan pada luaran vensim yang kemudian disimpan dalam bentuk excel dan diimplementasikan dalam bentuk dashboard dengan bantuan aplikasi Power BI.

6. Dengan hasil skenario yang telah didapatkan, maka skenario yang paling tepat untuk digunakan PT. PLN (Persero) APP Semarang dalam melakukan pemeliharaan dengan menggunakan manajemen aset adalah skenario nomor 2 karena pada skenario tersebut, untuk dapat mengoptimalkan pemeliharaan operasional aset yang optimal tidak hanya dilakukan dengan manajemen aset saja namun ditambahkan dengan memperbaiki/merawat aset yang memiliki kondisi tidak prima sehingga kondisi aset menjadi lebih optimal.

\section{DAFTAR PUSTAKA}

[1] N. B. B. Hartono, "Analisis Pemahaman Mahasiswa Akuntansi Terhadap Konsep Aset, Kewajiban, dan Ekuitas," J. Bisnis dan Akunt., vol. 13, no. 3, pp. 183-194, 2011.

[2] I. Wenzler, "Development of an Asset Management Strategy for a Network Utility Company," 2015.

[3] AAMCoG, "Australian Asset Management Collaborative Group: Code of Integrated Systems Strategic Asset Management," 2012.

[4] C. A. Lestari, "Analisa Penggunaan Gardu Sisipan Pada Penyulang Harimau untuk Meminimalisir Susut Teknis Dengan Aplikasi ETAP 12.6.0 Di PT. PLN (PERSERO) Rayon Rivai Palembang,” 2015.

[5] E. S. A. P. Kinanti, "Manajemen Aset Jaringan Distribusi Tenaga Listrik Untuk Meningkatkan Keandalan Jaringan Distribusi Menggunakan Sistem Dinamik (Studi Kasus: PT. PLN (Persero) APJ Surabaya Selatan)," J. Tek. Pomits, vol. 1, no. 1, pp. 1-3, 2014.

[6] S. AusNet, "ELECTRICITY DISTRIBUTION 5 YEAR ASSET MANAGEMENT PLAN," 2006.

[7] G. A. P. Richardson, Introduction to System Dynamics Modelling with Dynamo. London: MIT Press, 1986.

[8] J. J. D. E. K. P. D. K. Weygandt, Financial Accounting, IFRS Editi. John Wiley and Sons, Inc, 2012.

[9] Malabay, "Pendekatan Sistem Model Causal Loop Diagram Dalam Memahami Permasalahan Penerimaan Kuantitas Mahasiswa Baru Di Perguruan Tinggi Swasta, Jakarta,” 2008.

[10] J. J. Crisp, "Asset Management in Electricity Transmission Enterprise: Factors that affect Asset Management Policies and Practices of Electricity Transmission Enterprises and their Impact on Performance," 2004.

[11] S. Few, Information Dashboard Design. Italy: O'Reilly Media, 2006. [12] R. T. W. Y. P. D. Nurmalasari, "Informational Dashboard untuk Monitoring Sistem Drainase secara Real-Time," vol. 4, no. 3, 2015.

[13] P. P. (. P. D. P. P. B. J. B. B. S. TRANSMISI, PEDOMAN PEMELIHARAAN GARDU INDUK. 2015. 